\title{
The effects of dietary omega-3 polyunsaturated fatty acid supplementation on attention and impulsivity in an animal model of attention deficit/hyperactivity disorder (ADHD)
}

\author{
Ewelina Makulska-Gertruda, Joachim Hauser, Thomas-A. Sontag, and Klaus W. Lange \\ Department of Experimental Psychology, University of Regensburg, 93040 Regensburg, \\ Germany
}

Corresponding author: Klaus W. Lange, PhD, Professor, Department of Experimental Psychology, University of Regensburg, 93040 Regensburg, Germany

Submission date: February 28, 2014; Acceptance date: July 2, 2014; Publication date: July 3, 2014

\begin{abstract}
Background: Attention deficit/hyperactivity disorder (ADHD) is one of the commonest psychiatric disorders in children and adolescents. The main symptoms of ADHD are hyperactivity, inattention and impulsivity. Both etiology and neurobiological basis of ADHD are unknown. In this context, long-chain polyunsaturated fatty acids (LC-PUFAs), especially omega-3 (n-3) PUFAs, have become a focus of interest. The symptoms of ADHD have been suggested to be associated with a deficiency of n-3 PUFAs. In addition, the impact of a supply of dietary n-3 PUFAs in the treatment of ADHD has frequently been discussed.
\end{abstract}

Objective: The aim of the present study was to examine the influence of $n-3$ PUFA supplementation on attention and impulsivity in the spontaneously hypertensive rat (SHR) which has been proposed to be a valid genetic animal model of ADHD.

Methods: Seven-week-old male SHRs were randomly divided into two groups of 15 rats and fed one of two experimental diets (n-3 PUFA-enriched or n-3 PUFA-deficient) prior to and during behavioral testing. Attention and impulsivity were assessed using a three-choiceserial-reaction-time-task (3CSRTT) which is based on the five-choice-serial-reaction-timetask. The experiment was performed with three-month-old rats.

Results: Our findings demonstrate a marked difference between groups regarding impulsivity but not attention. The n-3 PUFA-enriched diet significantly reduced impulsivity in SHRs compared with rats fed with the n-3 PUFA-deficient diet.

Conclusion: The present data show a decrease in impulsivity following a dietary n-3 PUFA supplementation, but no changes in attention. A possible explanation for these results is that the attention displayed by SHR may not be linked to n-3 PUFA supply. It is important to note that inattention and impulsiveness are two of the main symptoms of ADHD. Our results 
regarding dietary n-3 PUFA supply may support the positive findings in human studies demonstrating that n-3 PUFA administration can improve the cognitive or behavioral symptoms in children with ADHD.

Key words: omega-3 polyunsaturated fatty acid, animal model, spontaneously hypertensive rat, attention, impulsivity, attention deficit/hyperactivity disorder

\section{INTRODUCTION:}

Attention-deficit/hyperactivity disorder (ADHD) is one of the most frequently diagnosed psychiatric disorders of childhood and adolescence $[1,2]$. This mental disorder affects about 3-5\% of all children and adolescents [3]. According to the recently published 5th edition of the Diagnostic and Statistical Manual of Mental Disorders (DSM-5) [4], ADHD has a relatively heterogeneous clinical profile which manifests itself before the twelfth year of life. This disorder is characterized by excessive motor activity, inattention with an increase in distractibility, impulsiveness and disturbances of psychosocial adaptation [5-8]. Dysfunctioning of noradrenergic and dopaminergic neurotransmission appears to play an important role in the pathophysiology for ADHD [9-12]. The etiology and underlying neurobiology are still unknown [13].

Nutrition including the role of long-chain polyunsaturated fatty acids (LC-PUFAs) has become a focus of debate regarding the possible causes of ADHD. LC-PUFAs such as omega-6 (n-6) and omega-3 (n-3) PUFAs play a significant role in the development and functioning of the brain [14]. Deficits and imbalances of these fatty acids can therefore have a significant impact on mental illness [15]. In this context, LC-PUFAs have become a focus of research interest in ADHD [15].

Some studies have shown that blood plasma n-3 PUFA levels are reduced in children and adults with symptoms of ADHD [16, 17]. These deficits are also linked to behavioral problems and learning difficulties [18]. In comparison with a control group, decreased levels of arachidonic acid (AA, C20:4 n-6) and docosahexaenoic acid (DHA, C22:6 n-3) were found in erythrocytes of children and adolescents with $\operatorname{ADHD}[16,17,19,20]$. Further studies could demonstrate an increase in the ratio of n-6/n-3 PUFA (AA/eicosapentaenoic acid (EPA, C20:5 n-3)) in the plasma of children and adults with ADHD [16, 17, 21]. In addition, supplementation studies with LC-PUFA found improvements in behavioral ratings [22-24] which were associated with a decrease in the plasma AA/EPA ratio [24]. Randomized controlled experiments have shown that n-3 PUFA administration can reduce impulsivity and attention problems in children with ADHD symptoms compared with a placebo group [25-28].

Human studies have suggested a link between n-3 PUFAs and ADHD [e.g. 18]. Humans are incapable of synthesizing PUFAs and dietary intake is therefore necessary [29, 30]. However, it is difficult to regulate PUFA ingestion in humans and a possible connection between n-3 PUFAs and ADHD can be more easily assessed in animal studies. It has been shown that long-term deficiency of n-3 PUFAs in rats causes changes in central dopaminergic neurotransmission [31-33]. Dopamine appears to play an important role in the neurobiology of ADHD [34]. In addition, major alterations caused by an n-3 PUFA shortage were observed in the frontal cortex of animals [32]. The underlying mechanisms are not 
completely understood. Altered neurotransmission seems to be caused by changes in the concentration of LC-PUFAs in the neuronal membrane [35, 36].

Several studies have shown that n-3 PUFA deficiency in rodents is associated with an increase in activity [37, 38], impairments in spatial learning [39, 40], working memory [41] and olfactory discrimination learning [42] as well as with aggression and depression [43]. These findings suggest that a depletion of n-3 PUFAs has an influence on cognitive processes and behavior. Chalon et al. [44] demonstrated that n-3 PUFA supplementation reduced motor activity in rats. Carrie et al. [45] showed that the intake of n-3 PUFAs leads to a decrease in locomotor activity among older mice. In addition, a marked difference in open field locomotor activity was observed between spontaneously hypertensive rat (SHR) fed with n-3 PUFA-deficient food and SHR on an n-3 PUFA-enriched diet [46]. Furthermore, several studies observed cognitive improvements in n-3 PUFA-depleted rats receiving a supplementation diet at birth and after weaning [47-50]. Dervola et al. [51] have demonstrated that an n-3 PUFA supply in SHR dams decreases the non-reinforcement spontaneous locomotion and enhances the reinforcement-induced attention in the progeny of male SHRs. These investigations suggest that the supply of n-3 PUFAs can lead to a decrease in locomotor activity and may have some impact on cognitive performance in animals.

However, only a few animal studies have investigated LC-PUFAs and behavior with regard to the ADHD main symptoms. A link has been demonstrated between n-3 PUFAs and changes in motor activity in animals $[37,38,46]$. To our knowledge, there is only one study that has assessed attention deficits, impulsivity and hyperactivity aspects [51]. Similarly, the beneficial effect of n-3 PUFA supplementation has not yet been demonstrated. Since ADHD has a genetic basis, more attention should be paid to genetic animal models of ADHD such as the SHR [52, 53], particularly as these rodents show a natural lack of DHA in their neuronal cell membranes [54].

The aim of the present study was to investigate the effect of an n-3 PUFA-enriched diet versus an n-3 PUFA-deficient diet on attention and impulsivity in SHRs using the threechoice-serial-reaction-time-task (3CSRTT).

\section{METHODS:}

Animals: Seven-week-old male SHR were obtained from Charles River Laboratories (Sulzbach, Germany). They were kept in standard cages on a $12 \mathrm{~h}$ light-dark cycle (light from 7:00 h - 19:00 h). Room temperature was maintained at $22{ }^{\circ} \mathrm{C}+/-2{ }^{\circ} \mathrm{C}$ with an average humidity of $50 \%$. Water and food were provided ad libitum. Access to food was restricted during behavioral testing in order to increase the animals' motivation. Body weight was measured daily. A weight reduction of more than 10-15\% was avoided in order to prevent stress [55, 56] and subsequent changes in the dopaminergic system [57].

The rats were randomly divided into two groups of 15 rats and fed one of two experimental diets from the day of their arrival and throughout the testing period (3CSRTT), i.e the diets were provided for a total of 16 weeks (six weeks after arrival and 10 weeks of testing). The two experimental diets, the n-3 PUFA-enriched (n-3 Rich) diet and the n-3 PUFA-deficient (n-3 Def) diet, were prepared by Ssniff, Soest, Germany. Both diets were based on the American Institute of Nutrition-93 G (AIN93G) and meet all the current nutrition standards for rat growth [58]. The fatty acid composition of the diets is shown in Table 1. The diets were stored at $-20{ }^{\circ} \mathrm{C}$ and provided fresh daily. The experiment was performed with three-month-old rats. 
Table 1. Fatty acid composition of the experimental diets (Ssniff Spezialdiäten, Soest, Germany)

\begin{tabular}{lcc}
\hline & $\begin{array}{c}\text { n-3 PUFA-enriched } \\
\text { diet }\end{array}$ & $\begin{array}{c}\text { n-3 PUFA-deficient } \\
\text { diet }\end{array}$ \\
\hline Energy (Atwater), MJ/kg* & 17.1 & 17.1 \\
kJ\% protein & 18 & 18 \\
kJ\% carbohydrates & 60 & 60 \\
kJ\% Fat & 22 & 22 \\
& & \\
Fatty acids, \% of the diet & & \\
C 6:0 & 0.05 & 0.05 \\
C 8:0 & 0.59 & 0.62 \\
C 10:0 & 0.47 & 0.49 \\
C 12:0 & 3.48 & 3.64 \\
C 14:0 & 1.35 & 1.41 \\
C 16:0 & 0.84 & 0.85 \\
C 18:0 & 0.29 & 0.28 \\
C 20:0 & 0.01 & 0.01 \\
C 18:1 & 0.82 & 0.77 \\
C 18:2 n6 & $\mathbf{1 . 5 4}$ & $\mathbf{1 . 5 8}$ \\
C 18:3 n3 & $\mathbf{0 . 2 7}$ & $\mathbf{0 . 0 1}$ \\
\hline
\end{tabular}

* physiological fuel value

Apparatus: The task is based on the five-choice-serial-reaction-time-task [59, 60]. In the present study, a three-choice variant of the paradigm was used (holes no. 3, 5, 7). The remaining unused holes were covered. The experiment was performed using four ventilated wooden chambers (Campden Instruments, Loughborough, Leicestershire, England) which included four stainless steel boxes (26 x $26 \mathrm{~cm}$ horizontally and approximately $30 \mathrm{~cm}$ high). The task was performed with a house light (3-Watt light bulb), three cue holes (each about 2 $\mathrm{cm}$ in diameter) with internal light-emitting diodes (3 Watt) and an illuminated food tray on the wall opposite to the cue holes. The three cue holes were arranged horizontally on one curved rear wall and placed about $2 \mathrm{~cm}$ from the floor (stainless steel grid). The distance between adjacent holes was $6 \mathrm{~cm}$. Nose pokes into the cue holes and the food tray were registered by photocells. A correct response, consisting of a nose poke into a lit cue hole was rewarded with a food pellet $(45 \mathrm{mg}$ dustless sucrose pellets, Bio-Serv, Frenchtown, New Jersey, USA), which was delivered into the food tray. Premature responses during the intertrial interval (ITI), incorrect responses into an unlit cue hole or not responding after 
stimulus presentation (an omission) resulted in a 5-second time-out period in which the house light was turned off. The start of the next trial was signaled automatically by illumination of the house light and food tray, and began with a nose poke of the rats into the food tray.

Procedure: The 3CSRTT comprised three phases - habituation (2 days), training (8 weeks) and test (5 days) (see Instruction Manual for MKII Rat 5CSRT [61]). After completion of the training, the stimulus duration was fixed at $2 \mathrm{~s}$ regardless of the performance. A session ended after either 30 minutes or 60 rewards, whichever occurred first. The ITIs were varied randomly between $1.5 \mathrm{~s}, 2.5 \mathrm{~s}, 3.5 \mathrm{~s}, 4.5 \mathrm{~s}$ (short ITI) in order to assess attention and between $5.5 \mathrm{~s}, 6.5 \mathrm{~s}, 7.5 \mathrm{~s}, 8.5 \mathrm{~s}$ (long ITI) to quantify impulsivity.

Statistics: The following parameters concerning impulsive behavior were analyzed: rate of premature responses (ratio of number of premature responses/total number of trials completed), number of premature responses (nose poke responses during ITI), number of time-out responses (nose poke responses during time-out period). The following parameters concerning activity of responses were examined: total number of trials completed and total correct and incorrect responses. In addition, the following parameters regarding attention were investigated: number of correct responses, number of commission errors (false reaction) and number of omission errors (missed reactions). Statistical analyses were performed using the nonparametric Mann-Whitney U-Test (between subjects design), an alpha level of 0.05 was applied. A mean value for each animal was calculated in order to compare the differences between the n-3 fatty acid groups. The analyses were carried out using the statistical package PASW 18.0 for Windows.

Ethics: The present experiment was carried out in accordance with the National Institutes of Health Guide for the Care and Use of Laboratory Animals (NIH publication No. 86-23, revised 1985).

\section{RESULTS:}

Body weight: The two experimental diets, i.e. n-3 Rich and n-3 Def, had no significant effect on the body weight of the rats (data not shown).

3CSRTT: In regard to the comparison between the n-3 Rich and the n-3 Def groups, statistically significant differences were found in the "rate of premature responses". The ratio of the number of premature responses to the total number of trials completed is significantly higher in the n-3 Def group than in the n-3 Rich rats. There are no significant differences in the nose poke responses during ITI and the number of time-out responses. However, the n-3 Def rats showed more premature responses than those in the n-3 Rich group. Furthermore, the n-3 Rich group showed fewer nose poke responses during the time-out period than the n-3 Def animals. All values regarding the rate of premature responses, the number of premature responses and the number of time-out responses of the n-3 Rich and the n-3 Def groups are given in Table 2 .

Table 2. Effects of n-3 PUFA deficiency and supplementation on impulsivity in the 3CSRTT test (long ITI) in SHR 


\begin{tabular}{llll}
\hline & $\begin{array}{l}\text { Rate of } \\
\text { premature responses }\end{array}$ & $\begin{array}{l}\text { Number of premature } \\
\text { responses }\end{array}$ & $\begin{array}{l}\text { Number of time-out } \\
\text { responses }\end{array}$ \\
\hline $\begin{array}{l}\text { n-3 Rich } \\
\text { group }\end{array}$ & $0.88 \pm 0.34^{*}$ & $13.65 \pm 1.39$ & $10.07 \pm 1.31$ \\
$\begin{array}{l}\boldsymbol{n} \text {-3 Def } \\
\text { group }\end{array}$ & $1.23 \pm 0.20$ & $16.73 \pm 1.87$ & $14.57 \pm 1.79$ \\
p-value & $\mathbf{0 . 0 0 7}$ & $\mathbf{0 . 2 4 5}$ & \\
& & & $\mathbf{0 . 0 8 5}$ \\
& & -1.162 & -1.723 \\
\hline -value & -2.717 & & \\
\hline
\end{tabular}

n-3 Def group = n-3 PUFA-deficient group; n-3 Rich group = n-3 PUFA-enriched group;

${ }^{*} \mathrm{p} \leq .05$ compared to $\mathrm{n}-3$ Def group; data are means \pm standard errors for 15 rats per group

The total number of trials completed is significantly higher in the n-3 Rich group than in the n-3 Def rats. Similarly, the total correct and incorrect responses were significantly higher in the n-3 Rich group than in the n-3 Def group. The total number of trials completed and the total correct and incorrect responses are presented in Table 3.

Table 3. Effects of n-3 PUFA deficiency and supplementation on the activity of responses in the 3CSRTT test (long ITI) in SHR

\begin{tabular}{lll}
\hline & $\begin{array}{l}\text { Total number of trials } \\
\text { completed }\end{array}$ & $\begin{array}{l}\text { Total correct and incorrect } \\
\text { responses }\end{array}$ \\
\hline n-3 Rich group & $25.72 \pm 2.05^{*}$ & $22.33 \pm 1.89^{*}$ \\
$\mathbf{n - 3}$ Def group & $19.36 \pm 2.16$ & $16.67 \pm 2$ \\
$\boldsymbol{p}$-value & $\mathbf{0 . 0 2 1}$ & $\mathbf{0 . 0 3 4}$ \\
$\mathbf{z - v a l u e}$ & & \\
& 2.302 & 2.116 \\
\hline
\end{tabular}

n-3 Def group = n-3 PUFA-deficient group; n-3 Rich group = n-3 PUFA-enriched group; $* \mathrm{p} \leq .05$ compared to $\mathrm{n}-3$ Def group; data are means \pm standard errors for 15 rats per group

There were no statistically significant differences concerning the number of correct responses or the number of commission and omission errors between groups. However, the n-3 Rich rats made more correct responses than the n-3 Def group in the test. Furthermore, the n-3 
Rich group made fewer commission errors and more omission errors than the n-3 Def animals. The number of correct responses, commission and omission errors of the n-3 Rich and the n-3 Def groups are given in Table 4.

Table 4. Effects of n-3 PUFA enrichment and deficiency on attention in the 3CSRTT test (short ITI) in SHR

\begin{tabular}{llll}
\hline & $\begin{array}{l}\text { Number of correct } \\
\text { responses }\end{array}$ & $\begin{array}{l}\text { Number of commission } \\
\text { errors }\end{array}$ & $\begin{array}{l}\text { Number of omission } \\
\text { errors }\end{array}$ \\
\hline $\begin{array}{l}\text { n-3 Rich } \\
\text { group }\end{array}$ & $23.32 \pm 1.28$ & $2.79 \pm 0.29$ & $7.68 \pm 0.80$ \\
$\begin{array}{l}\boldsymbol{n} \text {-3 Def } \\
\text { group }\end{array}$ & $22.61 \pm 1.44$ & $3.17 \pm 0.34$ & $6.88 \pm 0.77$ \\
$\begin{array}{l}\boldsymbol{p} \text {-value } \\
\text { nalue }\end{array}$ & 0.852 & 0.440 & 0.262 \\
& 0.187 & & 1.121 \\
\hline
\end{tabular}

n-3 Def group = n-3 PUFA-deficient group; n-3 Rich group = n-3 PUFA-enriched group;

data are means \pm standard errors for 15 rats per group

\section{DISCUSSION:}

Up until now the effects of n-3 PUFA supplementation on impulsive behavior and attention in rats have not sufficiently been investigated. The aim of the present study was therefore to elucidate the role of n-3 PUFAs by assessing impulsivity and attention in the SHR model with the 3CSRTT.

In the testing phase, there were no significant differences in body weight between the two n-3 groups. The differences in behavior between the n-3 groups are therefore not confounded by body weight. The present study attempted to investigate the effects of n-3 PUFA supplementation on impulsive behavior in rats as measured with the 3CSRTT. In comparison with the n-3 Def rats, the n-3 Rich diet significantly decreased the ratio of number of premature responses to total number of trials completed. This data suggests that an n-3 PUFA diet can improve impulsive behavior in SHR. Similar findings were reported by a study that investigated the effect of n-3 PUFA supplementation on impulsivity in SHR [51].

However, the choice-serial-reaction-time-task (CSRTT) assesses more parameters regarding impulsive behavior, i.e. the number of premature responses and the number of time-out responses. In regard to these factors no significant differences between $n-3$ groups were observed, although both parameters may show some improvements concerning impulsive behavior. The n-3 Def rats made more premature responses and more nose poke responses during the time-out period than the n-3 Rich group. This may indicate that impulsive behavior was reduced by dietary n-3 PUFA supplementation. This profile of results is consistent with previous animal studies demonstrating a recovery from PUFA deficiency by a supplementation diet [47-50]. However, as neither the number of premature responses 
nor the rate of time-out responses showed significant effects in the present study, our results call for further investigations.

Possible effects of dietary n-3 PUFAs on impulsive behavior in rats were insufficiently examined in the past. Previous studies investigating the effects of impulsivity on behavior used premature responses as sole parameter $[62,63]$. In our study, we suppose that it may be important to distinguish between impulsive premature responses and the generally increased response activity [64]. The CSRTT provides no valid parameters of the response activity. However, two parameters might indicate a general response activity, i.e. the total number of trials completed and the total correct and incorrect responses. The total number of trials completed is significantly higher in the n-3 Rich group than in the n-3 Def rats. In addition, the total correct and incorrect responses were significantly higher in the $n-3$ Rich group than in the n-3 Def group. Both parameters might show a significantly enhanced response activity of the n-3 Rich rats. One could say that rats fed with an n-3 PUFA-enriched diet show more rather than fewer answers, which may be associated with an enhanced motivation (being less "off-task").

Although the n-3 Rich rats were more active, as demonstrated by the total number of trials completed and the total correct and incorrect responses, they showed a significantly reduced premature behavior, as indicated by the "rate of premature responses". Moreover, the most commonly discussed parameters, i.e. the number of premature responses and the number of time-out responses, showed an effect in the same direction, although these comparisons failed to be statistically significant. These findings indicate that the rats' impulsive behavior cannot be seen as a simple result of an increase in activity [65]. Taken together, one may speculate that an n-3 PUFA supplementation cannot only reduce premature responses but can probably also increase the motivational state in the 3CSRTT. It would therefore be of interest to assess motivation and discuss it separately from impulsivity in future studies.

In regard to the effect of n-3 PUFA supplementation on the cognitive performance in the 3CSRTT, the present results indicate no significant improvements in attention in the SHR model. The attention parameters such as the number of correct responses and commission errors did not significantly differ between the $n-3$ groups.

The exact timing of the n-3 PUFA supply may be seen as a factor responsible for the low level of responses concerning attention in the SHR following the n-3 PUFA-enriched diet. In our study, the n-3 PUFA supplementation began post-weaning. A certain amount of n-3 PUFAs is accumulated in the nervous system of adult mammals and an increase occurs in the prenatal and early postnatal period, namely during brain growth [66-68]. This leads us to assume that an enrichment of n-3 PUFAs in the SHR has more important effects prenatally than in the post-weaning period. However, the aim of the present study was rather to investigate the effect of supplementation in terms of treatment. Further studies using the SHR model, especially in the prenatal phase, appear to be worthwhile.

In summary, one could conclude that the n-3 PUFA-enriched diet reduced the rats' impulsivity. However, dietary n-3 PUFA enrichment was compared with n-3 PUFA deficiency in this study. The question of whether or not an n-3 PUFA-deficient diet has some side-effects which can also influence the behavior of n-3 Def animals remains unanswered. It needs therefore to be investigated whether this effect can also be found when a balanced diet is used as control. 


\section{CONCLUSION:}

Taken together, the present findings show that the n-3 PUFA-enriched diet administered post -weaning had no significant effects on attention in SHRs as assessed in the 3CSRTT. In contrast, the data suggest a positive influence of the n-3 PUFA-enriched diet on impulsive behavior. Impulsiveness is one of main symptoms of ADHD. The present results may support the positive findings in previous human supplementation studies which demonstrated that the administration of n-3 PUFAs might improve the cognitive or behavioral symptoms in children with ADHD and may have some therapeutical effects [23, 24, 69-71].

Abbreviations: arachidonic acid (AA), attention deficit/hyperactivity disorder (ADHD), docosahexaenoic acid (DHA), eicosapentaenoic acid (EPA), long-chain polyunsaturated fatty acid (LC-PUFA), omega-3 polyunsaturated fatty acid (n-3 PUFA), omega-6 polyunsaturated fatty acid (n-6 PUFA), spontaneously hypertensive rat (SHR), three-choice-serial-reactiontime-task (3CSRTT)

Competing interests: The authors have no financial interests or conflicts of interest.

Authors' Contributions: All authors contributed to this study.

\section{REFERENCES:}

1. Posner K, Melvin GA, Murray DW, Gugga SS, Fisher P, Skrobala A, Cunningham C, Vitiello B, Abikoff HB, Ghuman JK, Kollins S, Wigal SB, Wigal T, McCracken JT, McGough JJ, Kastelic E, Boorady R, Davies M, Chuang SZ, Swanson JM, Riddle MA, Greenhill LL: Clinical presentation of attention-deficit/hyperactivity disorder in preschool children: the Preschoolers with Attention-Deficit/Hyperactivity Disorder Treatment Study (PATS). J Child Adolesc Psychopharmacol 2007, 17:547-562.

2. Schlack R, Holling H, Kurth BM, Huss M: The prevalence of attentiondeficit/hyperactivity disorder (ADHD) among children and adolescents in Germany. Initial results from the German Health Interview and Examination Survey for Children and Adolescents (KiGGS). Bundesgesundheitsblatt Gesundheitsforschung Gesundheitsschutz 2007, 50:827-835.

3. Barkley RA: Attenion-Deficit Hyperactivity Disorder: a handbook of diagnosis and treatment. London: Guilford Press; 2006.

4. American Psychiatric Association: Diagnostic and statistical manual of mental disorders: DSM-5. Washington, DC: American Psychiatric Publ; 2013.

5. Lange KW, Reichl S, Lange KM, Tucha L, Tucha O: The history of attention deficit hyperactivity disorder. Atten Defic Hyperact Disord 2010, 2:241-255.

6. Lange KW, Tucha L, Walitza S, Gerlach M, Linder M, Tucha O: Interaction of attention and graphomotor functions in children with attention deficit hyperactivity disorder. J Neural Transm Suppl 2007, 72:249-259.

7. Tucha O, Prell S, Mecklinger L, Bormann-Kischkel C, Kubber S, Linder M, Walitza $\mathrm{S}$, Lange KW: Effects of methylphenidate on multiple components of attention in children with attention deficit hyperactivity disorder. Psychopharmacology (Berl) 2006, 185:315-326. 
8. Tucha O, Walitza S, Mecklinger L, Sontag TA, Kubber S, Linder M, Lange KW: Attentional functioning in children with ADHD - predominantly hyperactiveimpulsive type and children with ADHD - combined type. J Neural Transm 2006, 113:1943-1953.

9. Arnsten AF: Catecholamine influences on dorsolateral prefrontal cortical networks. Biol Psychiatry 2011, 69:e89-99.

10. Hauser J, Sontag TA, Tucha O, Lange KW: The effects of the neurotoxin DSP4 on spatial learning and memory in Wistar rats. Atten Defic Hyperact Disord 2012, 4:9399.

11. Sontag TA, Hauser J, Kaunzinger I, Gerlach M, Tucha O, Lange KW: Effects of the noradrenergic neurotoxin DSP4 on spatial memory in the rat. J Neural Transm 2008, 115:299-303.

12. Sontag TA, Hauser J, Tucha O, Lange KW: Effects of DSP4 and methylphenidate on spatial memory performance in rats. Atten Defic Hyperact Disord 2011, 3:351-358.

13. Wankerl B, Hauser J, Makulska-Gertruda E, Reißmann A, Sontag T, Tucha O, Lange K:Neurobiologische Grundlagen der Aufmerksamkeitsdefizit-/Hyperaktivitätsstörung. Fortschritte der Neurologie. Psychiatrie 2014, 82:9-29.

14. McNamara RK, Carlson SE: Role of omega-3 fatty acids in brain development and function: potential implications for the pathogenesis and prevention of psychopathology. Prostaglandins Leukot Essent Fatty Acids 2006, 75:329-349.

15. Schuchardt JP, Huss M, Stauss-Grabo M, Hahn A: Significance of long-chain polyunsaturated fatty acids (PUFAs) for the development and behaviour of children. Eur J Pediatr 2010, 169:149-164.

16. Antalis CJ, Stevens LJ, Campbell M, Pazdro R, Ericson K, Burgess JR: Omega-3 fatty acid status in attention-deficit/hyperactivity disorder. Prostaglandins Leukot Essent Fatty Acids 2006, 75:299-308.

17. Stevens LJ, Zentall SS, Deck JL, Abate ML, Watkins BA, Lipp SR, Burgess JR: Essential fatty acid metabolism in boys with attention-deficit hyperactivity disorder. Am J Clin Nutr 1995, 62:761-768.

18. Stevens LJ, Zentall SS, Abate ML, Kuczek T, Burgess JR: Omega-3 fatty acids in boys with behavior, learning, and health problems. Physiol Behav 1996, 59:915-920.

19. Chen JR, Hsu SF, Hsu CD, Hwang LH, Yang SC: Dietary patterns and blood fatty acid composition in children with attention-deficit hyperactivity disorder in Taiwan. $\mathbf{J}$ Nutr Biochem 2004, 15:467-472.

20. Colter AL, Cutler C, Meckling KA: Fatty acid status and behavioural symptoms of attention deficit hyperactivity disorder in adolescents: a case-control study. Nutr $\mathbf{J}$ 2008, 7:8.

21. Germano M, Meleleo D, Montorfano G, Adorni L, Negroni M, Berra B, Rizzo AM: Plasma, red blood cells phospholipids and clinical evaluation after long chain omega3 supplementation in children with attention deficit hyperactivity disorder (ADHD). Nutr Neurosci 2007, 10:1-9.

22. Harding KL, Judah RD, Gant C: Outcome-based comparison of Ritalin versus foodsupplement treated children with AD/HD. Altern Med Rev 2003, 8:319-330.

23. Joshi K, Lad S, Kale M, Patwardhan B, Mahadik SP, Patni B, Chaudhary A, Bhave S, Pandit A: Supplementation with flax oil and vitamin C improves the outcome of 
Attention Deficit Hyperactivity Disorder (ADHD). Prostaglandins Leukot Essent Fatty Acids 2006, 74:17-21.

24. Sorgi PJ, Hallowell EM, Hutchins HL, Sears B: Effects of an open-label pilot study with high-dose EPA/DHA concentrates on plasma phospholipids and behavior in children with attention deficit hyperactivity disorder. Nutr J 2007, 6:16.

25. Richardson AJ, Puri BK: A randomized double-blind, placebo-controlled study of the effects of supplementation with highly unsaturated fatty acids on ADHD-related symptoms in children with specific learning difficulties. Prog Neuropsychopharmacol Biol Psychiatry 2002, 26:233-239.

26. Richardson AJ, Montgomery P: The Oxford-Durham study: a randomized, controlled trial of dietary supplementation with fatty acids in children with developmental coordination disorder. Pediatrics 2005, 115:1360-1366.

27. Sinn N, Bryan J: Effect of supplementation with polyunsaturated fatty acids and micronutrients on learning and behavior problems associated with child ADHD. J Dev Behav Pediatr 2007, 28:82-91.

28. Stevens LJ, Zhang W, Peck L, Kuczek T, Grevstad N, Mahon A, Zentall SS, Arnold LE, Burgess JR: EFA supplementation in children with inattention, hyperactivity, and other disruptive behaviors. Lipids 2003, 38:1007-1021.

29. Bourre JM, Francois M, Youyou A, Dumont O, Piciotti M, Pascal G, Durand G: The effects of dietary alpha-linolenic acid on the composition of nerve membranes, enzymatic activity, amplitude of electrophysiological parameters, resistance to poisons and performance of learning tasks in rats. J Nutr 1989, 119:1880-1892.

30. Yehuda S, Rabinovitz S, Mostofsky DI: Essential fatty acids are mediators of brain biochemistry and cognitive functions. J Neurosci Res 1999, 56:565-570.

31. Ahmad SO, Park JH, Radel JD, Levant B: Reduced numbers of dopamine neurons in the substantia nigra pars compacta and ventral tegmental area of rats fed an n-3 polyunsaturated fatty acid-deficient diet: a stereological study. Neurosci Lett 2008, 438:303-307.

32. Delion S, Chalon S, Herault J, Guilloteau D, Besnard JC, Durand G: Chronic dietary alpha-linolenic acid deficiency alters dopaminergic and serotoninergic neurotransmission in rats. J Nutr 1994, 124:2466-2476.

33. Delion S, Chalon S, Guilloteau D, Besnard JC, Durand G: alpha-Linolenic acid dietary deficiency alters age-related changes of dopaminergic and serotoninergic neurotransmission in the rat frontal cortex. J Neurochem 1996, 66:1582-1591.

34. Arnsten AF, Steere JC, Hunt RD: The contribution of alpha 2-noradrenergic mechanisms of prefrontal cortical cognitive function. Potential significance for attention-deficit hyperactivity disorder. Arch Gen Psychiatry 1996, 53:448-455.

35. Chalon S: Omega-3 fatty acids and monoamine neurotransmission. Prostaglandins Leukot Essent Fatty Acids 2006, 75:259-269.

36. Chalon S, Vancassel S, Zimmer L, Guilloteau D, Durand G: Polyunsaturated fatty acids and cerebral function: focus on monoaminergic neurotransmission. Lipids 2001, 36:937-944.

37. Frances H, Monier C, Clement M, Lecorsier A, Debray M, Bourre JM: Effect of dietary alpha-linolenic acid deficiency on habituation. Life Sci 1996, 58:1805-1816. 
38. Moriguchi T, Greiner RS, Salem N, Jr.: Behavioral deficits associated with dietary induction of decreased brain docosahexaenoic acid concentration. J Neurochem 2000, 75:2563-2573.

39. de Souza AS, Pacheco Lda C, Castro Pda S, Hokoc JN, Rocha MS, do Carmo M: Brain fatty acid profiles and spatial learning in malnourished rats: effects of nutritional intervention. Nutr Neurosci 2008, 11:119-127.

40. Fedorova I, Hussein N, Baumann MH, Di Martino C, Salem N, Jr.: An n-3 fatty acid deficiency impairs rat spatial learning in the Barnes maze. Behav Neurosci 2009, 123:196-205.

41. Wainwright PE, Xing HC, Ward GR, Huang YS, Bobik E, Auestad N, Montalto M: Water maze performance is unaffected in artificially reared rats fed diets supplemented with arachidonic acid and docosahexaenoic acid. J Nutr 1999, 129:1079-1089.

42. Greiner RS, Moriguchi T, Slotnick BM, Hutton A, Salem N: Olfactory discrimination deficits in n-3 fatty acid-deficient rats. Physiol Behav 2001, 72:379-385.

43. DeMar JC, Jr., Ma K, Bell JM, Igarashi M, Greenstein D, Rapoport SI: One generation of n-3 polyunsaturated fatty acid deprivation increases depression and aggression test scores in rats. J Lipid Res 2006, 47:172-180.

44. Chalon S, Delion-Vancassel S, Belzung C, Guilloteau D, Leguisquet AM, Besnard JC, Durand G: Dietary fish oil affects monoaminergic neurotransmission and behavior in rats. J Nutr 1998, 128:2512-2519.

45. Carrie I, Guesnet P, Bourre JM, Frances H: Diets containing long-chain n-3 polyunsaturated fatty acids affect behaviour differently during development than ageing in mice. Br J Nutr 2000, 83:439-447.

46. Hauser J, Makulska-Gertruda E, Reissmann A, Sontag T-A, Tucha O, Lange KW: The effects of nutritional polyunsaturated fatty acids on locomotor activity in spontaneously hypertensive rats. Atten Defic and Hyperact Disord 2014:1-5.

47. Carrie I, Clement M, de Javel D, Frances H, Bourre JM: Phospholipid supplementation reverses behavioral and biochemical alterations induced by $\mathrm{n}-3$ polyunsaturated fatty acid deficiency in mice. J Lipid Res 2000, 41:473-480.

48. Ikemoto A, Ohishi M, Sato Y, Hata N, Misawa Y, Fujii Y, Okuyama H: Reversibility of $n-3$ fatty acid deficiency-induced alterations of learning behavior in the rat: level of n-6 fatty acids as another critical factor. J Lipid Res 2001, 42:1655-1663.

49. Moriguchi T, Salem N, Jr.: Recovery of brain docosahexaenoate leads to recovery of spatial task performance. J Neurochem 2003, 87:297-309.

50. Takeuchi T, Fukumoto Y, Harada E: Influence of a dietary n-3 fatty acid deficiency on the cerebral catecholamine contents, EEG and learning ability in rat. Behav Brain Res 2002, 131:193-203.

51. Dervola KS, Roberg BA, Woien G, Bogen IL, Sandvik TH, Sagvolden T, Drevon CA, Johansen EB, Walaas SI: Marine omega-3 polyunsaturated fatty acids induce sexspecific changes in reinforcer-controlled behaviour and neurotransmitter metabolism in a spontaneously hypertensive rat model of ADHD. Behav Brain Funct 2012, 8:56.

52. Sontag TA, Tucha O, Walitza S, Lange KW: Animal models of attention deficit/hyperactivity disorder (ADHD): a critical review. Atten Defic Hyperact Disord 2010, 2:1-20. 
53. Sontag TA, Fuermaier AB, Hauser J, Kaunzinger I, Tucha O, Lange KW: Spatial memory in spontaneously hypertensive rats (SHR). PLoS One 2013, 8:e74660.

54. Narce M, Poisson JP: Age-related depletion of linoleic acid desaturation in liver microsomes from young spontaneously hypertensive rats. Prostaglandins Leukot Essent Fatty Acids 1995, 53:59-63.

55. Bear MF: Homosynaptic long-term depression: a mechanism for memory? Proc Natl Acad Sci U S A 1999, 96:9457-9458.

56. Deroche V, Marinelli M, Maccari S, Le Moal M, Simon H, Piazza PV: Stress-induced sensitization and glucocorticoids. I. Sensitization of dopamine-dependent locomotor effects of amphetamine and morphine depends on stress-induced corticosterone secretion. J Neurosci 1995, 15:7181-7188.

57. Pothos EN, Hernandez L, Hoebel BG: Chronic food deprivation decreases extracellular dopamine in the nucleus accumbens: implications for a possible neurochemical link between weight loss and drug abuse. Obes Res 1995, 4(Suppl 3):525-529.

58. Reeves PG, Nielsen FH, Fahey GC, Jr.: AIN-93 purified diets for laboratory rodents: final report of the American Institute of Nutrition ad hoc writing committee on the reformulation of the AIN-76A rodent diet. J Nutr 1993, 123:1939-1951.

59. Carli M, Robbins TW, Evenden JL, Everitt BJ: Effects of lesions to ascending noradrenergic neurones on performance of a 5-choice serial reaction task in rats; implications for theories of dorsal noradrenergic bundle function based on selective attention and arousal. Behav Brain Res 1983, 9:361-380.

60. Robbins TW: The 5-choice serial reaction time task: behavioural pharmacology and functional neurochemistry. Psychopharmacology (Berl) 2002, 163:362-380.

61. Campden Instruments: Instruction Manual for MKII Rat 5CSRT. Loughborough: Campden Instruments Limited; 2005.

62. Navarra R, Graf R, Huang Y, Logue S, Comery T, Hughes Z, Day M: Effects of atomoxetine and methylphenidate on attention and impulsivity in the 5-choice serial reaction time test. Prog Neuropsychopharmacol Biol Psychiatry 2008, 32:34-41.

63. Robinson ES, Eagle DM, Mar AC, Bari A, Banerjee G, Jiang X, Dalley JW, Robbins TW: Similar effects of the selective noradrenaline reuptake inhibitor atomoxetine on three distinct forms of impulsivity in the rat. Neuropsychopharmacology 2008, 33:1028-1037.

64. Koskinen T, Haapalinna A, Sirvio J: Alpha-adrenoceptor-mediated modulation of 5HT2 receptor agonist induced impulsive responding in a 5-choice serial reaction time task. Pharmacol Toxicol 2003, 92:214-225.

65. Robinson ES, Eagle DM, Economidou D, Theobald DE, Mar AC, Murphy ER, Robbins TW, Dalley JW: Behavioural characterisation of high impulsivity on the 5choice serial reaction time task: specific deficits in 'waiting' versus 'stopping'. Behav Brain Res 2009, 196:310-316.

66. Clandinin MT, Chappell JE, Leong S, Heim T, Swyer PR, Chance GW: Extrauterine fatty acid accretion in infant brain: implications for fatty acid requirements. Early Hum Dev 1980, 4:131-138.

67. Green P, Glozman S, Kamensky B, Yavin E: Developmental changes in rat brain membrane lipids and fatty acids. The preferential prenatal accumulation of docosahexaenoic acid. J Lipid Res 1999, 40:960-966. 
68. Martinez M: Tissue levels of polyunsaturated fatty acids during early human development. J Pediatr 1992, 120:129-138.

69. Rojas CV, Martinez JI, Flores I, Hoffman DR, Uauy R: Gene expression analysis in human fetal retinal explants treated with docosahexaenoic acid. Invest Ophthalmol Vis Sci 2003, 44:3170-3177.

70. Ross BM, McKenzie I, Glen I, Bennett CP: Increased levels of ethane, a non-invasive marker of n-3 fatty acid oxidation, in breath of children with attention deficit hyperactivity disorder. Nutr Neurosci 2003, 6:277-281.

71. Richardson AJ, Puri BK: The potential role of fatty acids in attentiondeficit/hyperactivity disorder. Prostaglandins Leukot Essent Fatty Acids 2000, 63:7987. 